\title{
Evaluation of performance quality of an advanced scope physiotherapy role in a hospital emergency department
}

This article was published in the following Dove Press journal:

Patient Related Outcome Measures

21 July 2015

Number of times this article has been viewed

J Morris'

K Vine'

K Grimmer ${ }^{2}$

'Physiotherapy Department, The Canberra Hospital, Cnr Hindmarsh Dr \& Yamba Dr, Garran, ACT, ${ }^{2}$ International Centre for Allied Health Evidence, University of South Australia, City East Campus, Adelaide, SA, Australia
Correspondence: J Morris Physiotherapy Department, The Canberra Hospital, Cnr Hindmarsh Dr \& Yamba Dr, Garran, ACT, 2605, Australia

Email jo.morris@act.gov.au
Background: Physiotherapists working in advanced and extended scope roles internationally make a difference to workflow, performance targets, and patient satisfaction in areas traditionally served by medicine and nursing.

Aim: To assess the impact of an advanced scope of practice physiotherapist (ASoP-PT) service in a large Australian hospital emergency department (ED) by measuring national service and triage category indicators, patient and staff satisfaction.

Methods: Consecutive patients consulting the ASoP-PT were recruited over 53 weeks following service inception. Descriptions of ASoP-PT activities and patients were collected. Performance was assessed against national ED indicators for length of stay and wait. Patient and staff perspectives were assessed independently by semi-structured interviews. The physiotherapist was formally trained to extended scope of practice including competency in medicines, prescription and application. The legislation prevented him from applying these skills, therefore he worked in an ASoP-PT role in ED.

Results: The ASoP-PT treated on average, 72 patients per month in ten shifts per fortnight, consulting patients aged from 1 to 88 years. Patients largely presented with musculoskeletal problems in triage Categories 4 and 5. There were shorter length of wait and length of stay, when the ASoP-PT was on shift. However overall compliance with national performance targets was similar with and without the ASoP-PT. Staff and patient satisfaction was high, particularly valuing the ASoP-PT's expertise in musculoskeletal injuries.

Conclusion: The ASoP-PT performed at least as well as other ED health care providers in meeting national triage targets. Had the legislation permitted his independent prescription of medicines, the ASoP-PT could have worked in an extended scope role, and his performance in meeting targets may have been better.

Keywords: advanced scope physiotherapy practice, emergency department, quality indicators, satisfaction

\section{Background}

Extended scope of practice (ESoP) physiotherapy roles have been established in the UK since the mid-1990s. ${ }^{1-3}$ There is no such equivalent in the US. ${ }^{4}$ A key reason for introducing these new roles in the UK was to take up activities relinquished by junior medical staff in the National Health Service (NHS), when enterprise bargaining restricted doctor work hours. ${ }^{5,6}$ The new physiotherapy roles ensured that hospitals could still meet the newly introduced service access targets. ${ }^{7,8}$ Much of the research into the impact of ESoP physiotherapy in the UK has reported on outcome measures of safety, cost, and access. ${ }^{8,9}$ However, because of the need to act quickly to ensure service continuity, the new physiotherapy roles were introduced 
without nationally-planned training or credentialing. ${ }^{10-12}$ As a result, physiotherapists (PTs) were trained and credentialed "in-house" in reading imaging, prescribing and using medicines (including injecting). ${ }^{10-12}$ While meeting local and national access requirements, in-house ESoP training meant that few ESoP-PTs could work in this same role across hospitals as their skills were not recognized.

There is an increasing interest in Australia regarding PTs extending their skills and performing new and novel roles. ${ }^{12-17}$ The drivers for this include escalating complex and chronic disease prevalence, an aging population, ensuring equity and access to health services, the changing nature of the medical workforce, patient expectations and PTs' desire to learn and practice new skills in new settings. ${ }^{18-20}$ These drivers have underpinned the development and implementation of new physiotherapy roles where practitioners have worked to the edge of, or beyond, traditional scope of practice. ${ }^{12,14,17,21}$ The area of practice which is central to delineation of the ESoP roles from advanced scope of practice (ASoP) roles is the use of medicines (providing advice, administering and/or prescribing). Introduction of formally-recognized ESoP physiotherapy roles in Australia, such as those practiced in the UK, has been constrained due to legislative restriction on medicines use, availability of formal training to underpin role extension, and lack of clinical career pathways within the public system. ${ }^{16,22}$ We previously showed that a formallytrained PT working in a doctor-supervised ESoP role in an Australian orthopedic outpatient clinic incurred no greater risk of adverse events than other discipline health practitioners, particularly in terms of medicines use or injecting outcomes. ${ }^{23}$

Clarity on ASoP and ESoP physiotherapy roles has been achieved by the broad adoption of the Australian Physiotherapy Association ${ }^{24}$ definitions; however there are still grey areas open to interpretation:

- $\mathrm{ASoP}$ - a role that is within the currently recognized scope of practice for that profession, but which through custom and practice has been performed by other professions. The advanced role may require additional training as well as significant professional experience and competency development.

- Extended scope of practice - a role that is outside the currently recognized scope of practice and one that requires some method of credentialing following additional training, competency development, and significant professional experience, as well as legislative change.

\section{Physiotherapy practice in Australian emergency departments (EDs)}

To date in Australia, the provision of physiotherapy services in ED occurs in two ways:

- PTs undertake "within scope" roles as secondary contact practitioners, where they generally provide services on referral from ED medical practitioners. This clinical care mostly focuses on acutely unwell patients (such as stroke, acute chest problems, falls) and discharge safety. ${ }^{12,15}$

- PTs assume independent primary contactroles..$^{15}$ They assess and treat patients in the same manner as doctors or advanced practice nurse/nurse practitioners. Many EDs consider this to constitute ASoP, as they recruit highly trained PTs to undertake complex assessment and treatment beyond or to the margins of traditional physiotherapy scope of practice. This role includes ordering and interpreting diagnostic tests ${ }^{12,15}$ However current Australian legislation does not support the prescription of medicines by formally-trained PTs (as would occur in an ESoP role) (see Supplementary material for reference to the Medicines and Poisons Acts around Australia). Thus there are limited opportunities in Australia to explore the full benefits of employing an ESoP-PT in ED, in terms of demonstrating competence and meeting national triage performance targets.

\section{Australian ED targets}

There are two sets of Australian ED targets. 1) Time to assessment in ED. Patients presenting to ED are triaged into one of five Australian Triage Scales (ATS) (see Table 1). ${ }^{25}$ These categories reflect agreed Australian benchmarks for time to first assessment in ED. Categories 1-3 deal with emergencies and potentially life-threatening conditions (Category 1 to be seen immediately, Category 2 to be seen within 10 minutes, Category 3 to be seen within 30 minutes). Categories 4 and 5 reflect less urgent conditions, with waiting times for assessment allowed up to 60 and 120 minutes respectively. From a physiotherapy perspective, Category 4 might be a sprained ankle, and Category 5 might be an acute flare of a chronic injury. 2) Time to discharge from ED. The Australian National Emergency Access Target (NEAT) was introduced in 2012, stating: "The goal of the NEAT is to increase the proportion of ED patients who physically leave the ED (for admission to hospital, referral to another hospital, or discharge) in 4 hours or less". ${ }^{19}$ NEATs are annual reporting benchmarks set for EDs in Australia from January 2012 to December 2015, to encourage hospital EDs to strive for continual improvement in patient care. 
Table I Descriptions of ATS categories used in Australian hospital emergency departments, and associated ACEM targets

\section{ATS Category I}

Need for resuscitation. People in this group are critically ill and require immediate attention. Most arrive at the emergency department by ambulance. This group includes people whose heart may have stopped beating, whose blood pressure may have dropped to dangerously low levels, who may be barely breathing or have stopped breathing, who may have suffered a critical injury, or who may have had an overdose of intravenous drugs and be unresponsive.

ACEM maximum waiting time: seen immediately

ACEM performance indicator threshold: $100 \%$

\section{ATS Category 2}

Emergency - people in this group will probably be suffering a critical illness or very severe pain. For example, the group includes people with serious chest pain likely to be related to a heart attack, people with difficulty breathing and people with severe fractures.

ACEM maximum waiting time: patients seen within 10 minutes ACEM performance indicator threshold: $80 \%$

\section{ATS Category 3}

Urgent - people in this group include patients suffering from severe illnesses, people with head injuries but who are conscious, and people with major bleeding from cuts, major fractures, persistent vomiting or dehydration.

ACEM maximum waiting time: patients seen within 30 minutes ACEM performance indicator threshold: $75 \%$

\section{ATS Category 4}

Semi-urgent. People in this group usually have less severe symptoms or injuries, although the condition may be potentially serious. Examples include people with mild bleeding, a foreign body in the eye, a head injury (but where the patient never lost consciousness), a sprained ankle, possible bone fractures, abdominal pain, migraine or earache. ACEM maximum waiting time: patients seen within 60 minutes ACEM performance indicator threshold: $70 \%$

\section{ATS Category 5}

Non-urgent. People in this group usually have minor illnesses or symptoms that may have been present for more than I week, like rashes or minor aches and pains. The group includes people with stable chronic conditions who are experiencing minor symptoms.

ACEM maximum waiting time: patients seen within 120 minutes ACEM performance indicator threshold: $65 \%$

Abbreviations: ATS, Australian Triage Scales; ACEM, Australasian College for Emergency Medicine.

\section{Musculoskeletal skills}

PTs have recognized skills in treating musculoskeletal conditions which generally present as ATS Categories 4 or 5 , including differential diagnosis of non-musculoskeletal conditions that may "masquerade" as musculoskeletal conditions (for instance deep vein thrombosis or referred visceral pain). ${ }^{26-28}$

In the UK, PTs working in ED treating musculoskeletal conditions (in ASoP or ESoP roles) achieve similar patient outcomes to medical and nurse practitioner colleagues. ${ }^{29,30}$ These authors reported that when patients were managed by PTs, there was no additional financial burden to the ED (in terms of salary, equipment, or tests). Moreover there were no service-related changes in the broader health system such as no change in re-presentations, referral patterns, or adverse outcomes. ${ }^{29}$ Jibuike et al ${ }^{31}$ demonstrated that the presence of PTs in ED saved medical time. This study also reported the diagnostic accuracy of PTs, when their results were compared with subsequent magnetic resonance imaging (MRI). Two experimental studies conducted in the last 10 years found greater patient satisfaction with the ED care provided by PTs, when compared with nursing and medical colleagues' care., ${ }^{1,30}$ These studies also reported that PT care in ED reduced patient waiting times, decreased length and number of "stops" in the patient journey, and provided more timely access to appropriate treatment and investigations. ${ }^{1,30}$

Around the country, Australian EDs have been trialing advanced scope of practice physiotherapist (ASoP-PT) services over the last 5 years. These services have generally been introduced as pilot studies in workforce reform projects, which cease when funding ceases. Pilot studies often run from 6 to 9 months, and in this time span it is difficult to demonstrate consistency of performance, quality standards or effectiveness. This paper describes evaluation findings of a rare 11-month-longpilot of ASoP-PT services in one large Australian public hospital ED. The aims of the evaluation were to describe whom the ASoP-PT consulted (in terms of age, condition, and ATS categories), patient treatments, patient flow, compliance with the relevant NEAT benchmark, and comparison of ASoP-PT NEAT compliance with that of other health care providers treating similar patients. Patient and staff perspectives were also reported, regarding the ASoP-PT service. The hypotheses underpinning this evaluation were that the ASoP-PT service would mostly consult ATS Category 4 and 5 patients, comply with the NEAT 4-hour discharge benchmark, and be well received by patients and ED staff. The evaluation was conceived as a way of demonstrating that, should the hypotheses be supported, the ASoP-PT service would continue.

\section{Methodology Ethics}

Ethics approval was provided by the administering hospital (ETH:6.10.259).

\section{Setting for the pilot study}

The Canberra Hospital (TCH) is a tertiary teaching hospital and trauma center for a catchment of 550,000 people in Australian Capital Territory (ACT) and Greater New South Wales. It has 43 beds and ED typically treats 180 patients per day, 
with on average, one in ATS Category 1, 26 in Category 2, 58 in Category 3, 78 in Category 4, and 17 in Category 5. There are usually between 19 and 23 nurses and between five and 15 (night and morning shift, respectively) medical doctors on duty at any one shift in ED.

\section{Driver for change}

Like many other Australian hospital EDs, TCH ED has experienced increasingly heavy workloads since 2009, which has placed significant stresses on medical staff to meet national ED targets. ACT Health has been allocated $\$ 3.3$ million over 4 years, contingent on performance in meeting the NEAT targets by 30 June 2016. In 2011-2012, ACT Health ED waiting times were significantly longer than the national average as evidenced by the My Hospitals Website. ${ }^{32}$ In 2011-2012, only $54 \%$ of patients departed TCH ED within the NEAT specification of discharge within 4 hours of arrival. Just $45 \%$ Category 4 patients and $78 \%$ Category 5 patients met these recommended time frames (the national average being $66 \%$ and $89 \%$, respectively). ${ }^{32,33}$ There is an additional burden on this hospital ED, as the Productivity Commissions Report on Government Services ${ }^{34}$ indicates that the ACT has the lowest availability of full-time equivalent (FTE) general practitioners per capita of any Australian urban area. Thus many patients with emergency health issues attend the hospital ED as their first choice, as they know that they will be seen on the same day. This additional patient load mostly reflects Australasian College for Emergency Medicine (ACEM) triage Categories 4 and 5.

\section{Study design}

A prospective 53-week observational study (October 26, 2011 to November 2, 2012) was conducted of consecutive patients presenting to ED who were consulted in the "Fast Track" an area of ED designated for less urgent, ambulatory patients, of which $60 \%$ of the clinical load was musculoskeletal presentations (thus likely to be mostly ATS Categories 4 and 5). "Fast Track" is a subsection of hospital ED set up in 2007 to specifically manage patients with minor illnesses and injuries.

\section{Description of the physiotherapy ED service}

At the time of the evaluation, there was usually a two and a half FTE physiotherapy service in ED. One FTE provided a within scope (usual) physiotherapy role (working in secondary contact roles), this PT is employed at a Health Professional 2 level (http://www.jobs.act.gov.au/_data/assets/ pdf file/0012/530031/Health-Professionals-Agreement. pdf), and one ASoP-PT, working mainly in primary contact and employed at a Health Professional 4 level (for further information regarding ACT Health Professional levels please see URL). As a means of providing increased hours of operation a 0.5 FTE in-scope primary contact PT was employed (Health Professional 3 level) who had not completed the extended scope physiotherapy training and therefore was unable to independently manage patients with fractures or review diagnostic images. The ASoP-PT worked in a shift pattern. A usual day shift covered the hours between $8.30 \mathrm{am}$ and $6 \mathrm{pm}$ and an evening shift covered the hours of $2 \mathrm{pm}-10$ pm. When the ASoP-PT was rostered for an evening shift, an in-scope, primary contact PT would provide the morning Fast Track service.

The ASoP-PT could have worked in an ESoP role in ED because of his formal, accredited training. However local legislative constraints precluded him from independently providing medication management. ${ }^{35}$ Thus for research purposes, his role was considered as ASoP. Where indicated, he suggested medication for his patients that was subsequently prescribed by an ED medical doctor.

The ASoP-PT worked in Fast Track in 7.5-hour shifts (day or evening). Shift organization corresponded with peak times in ED for presentation of Categories 4 or 5 patients (for instance, afternoon shifts on weekends to deal with sporting injuries). When there was "down time" between patients (which was rare), the PT wrote up notes and completed data collection forms. Mostly between patient consultations, the PT was checking on imaging and other test results, organizing consultations from teams outside ED, such as orthopedics, and obtaining medical prescriptions for drugs that he considered necessary, but was unable to legally prescribe.

\section{Patient assignment to Fast Track}

All patients presenting to ED were initially triaged into ATS categories by the ED triage nurses. Appropriate patients, mostly Categories 4 and 5 patients, were allocated to Fast Track, in which consultation could be with the ASoP-PT, advanced scope nurses, a nurse practitioner, or medical doctors. All patients, irrespective of whom performed the consultation, were consented in the usual manner.

\section{Evaluation measures of ASoP-PT service}

Data on length of wait (LoW) (relative to ATS categories) and length of stay (LoS) (4-hour NEAT target) were collected routinely on the ED patient tracking system (ED Information System) on all ED patients. Additional patient and advanced 
practice activity data were collected independently by the ASoP-PT because routine hospital data collection process did not include the necessary physiotherapy service evaluation items. He used a purpose-built paper-based form to collect patient demographics, nature of contact with ED PTs (primary or secondary), PT shift pattern and hours of work, and nature of patient presentation. The data were collated for evaluation purposes by an independent project officer using a purpose-built Microsoft Excel file. Where data were inadequately described on the form, she queried it with the PT prior to data entry.

To specifically compare performance of all Fast Track primary care providers who consulted patients with similar ATS categories data were extracted from the ED Information System on waiting times and LoS, and types of patient presentation for the primary contact PT, advanced care nurses (which included one nurse practitioner), and doctors.

To provide context around the types of patients who consulted the ASoP-PT, the broad ED diagnostic groupings ${ }^{36}$ of his patients and those seen by doctors and nurse practitioners were compared. Highlighted in the diagnostic list (Table 2), are those diagnostic groups with over 500 presentations,

Table 2 Diagnostic group classifications for all presentations to emergency department during the evaluation period, highlighting classifications with $>500$ presentations

\begin{tabular}{|c|c|}
\hline \multicolumn{2}{|c|}{ International Classification for Diseases (ICD codes) } \\
\hline$A$ and $B$ & Certain infectious and parasitic diseases (205) \\
\hline C & Neoplasms (3) \\
\hline $\mathrm{D}$ & $\begin{array}{l}\text { Diseases of the blood and blood forming organs and } \\
\text { certain disorders of the immune mechanism (I0) }\end{array}$ \\
\hline $\mathrm{E}$ & Endocrine, nutritional and metabolic disorders (13) \\
\hline $\mathrm{F}$ & Mental, behavioral, and neurodevelopment disorders (63) \\
\hline G & Diseases of the nervous system (53) \\
\hline $\mathrm{H}$ & Diseases of the ear and mastoid process (808) \\
\hline I & Diseases of the circulatory system (22I) \\
\hline J & Diseases of the respiratory system (272) \\
\hline K & Diseases of the digestive system (368) \\
\hline $\mathrm{L}$ & Diseases of the skin and subcutaneous tissue (52I) \\
\hline M & $\begin{array}{l}\text { Diseases of the musculoskeletal system and connective } \\
\text { tissue (1554) }\end{array}$ \\
\hline $\mathrm{N}$ & Diseases of the genitourinary system (184) \\
\hline O & Pregnancy, childbirth, and the puerperium (36) \\
\hline$P$ & Certain conditions originating in the perinatal period $(I)$ \\
\hline Q & $\begin{array}{l}\text { Congenital malformations, deformations, and } \\
\text { chromosomal abnormalities ( } 3 \text { ) }\end{array}$ \\
\hline $\mathrm{R}$ & $\begin{array}{l}\text { Symptoms, signs, and abnormal clinical and laboratory } \\
\text { findings, not elsewhere classified (620) }\end{array}$ \\
\hline S & $\begin{array}{l}\text { Injury, poisoning, and certain other consequences of } \\
\text { external causes }(6478)\end{array}$ \\
\hline $\mathrm{T}$ & $\begin{array}{l}\text { Injury, poisoning, and certain other consequences of } \\
\text { external causes }(951)\end{array}$ \\
\hline W-Y & External causes of morbidity and mortality (2345) \\
\hline Z & Factors influencing health status (2097) \\
\hline
\end{tabular}

extracted from routinely collected data collected during the evaluation period in ATS Categories 4 and 5.

\section{Qualitative measures of ASoP-PT service}

Patient and staff perspectives on the ASoP-PT service were collected by an independent PT using semi-structured interviews from:

- the ASoP-PT provided information to random selection of patients seeking their consent for telephone follow-up. An independent project officer would then contact the participants by phone and conduct a semi-structured interview.

A selection of APNs, medical officers, and other PTs who worked with the ASoP-PT in Fast Track were approached by the project officer and face-to-face semi-structured interviews were performed, recorded, and transcribed. All interviews were independently transcribed for analysis purposes. The semi-structured questions are provided in Table 3.

\section{Analysis}

All analysis of data was undertaken by two researchers who were independent of the data collection processes in ED, and

Table 3 Interview questions

\begin{tabular}{|c|c|}
\hline atie & estions \\
\hline $\begin{array}{l}\text { Were you happy with the } \\
\text { care that you received in } \\
\text { Emergency? } \\
\text { Were you aware that you } \\
\text { were seeing a physiotherapist } \\
\text { and not a doctor? } \\
\text { Would you have preferred } \\
\text { to have seen a doctor? } \\
\text { What aspects of your care } \\
\text { did you particularly like? } \\
\text { Do you have any concerns } \\
\text { regarding the treatment } \\
\text { that you received? } \\
\text { How does it compare to } \\
\text { previously Canberra Hospital } \\
\text { Emergency Department } \\
\text { experiences that you've had? } \\
\text { How do you think your care } \\
\text { could have been improved? } \\
\text { How long did you have to } \\
\text { wait for treatment? } \\
\text { Would you recommend } \\
\text { this service to others? } \\
\text { Is there anything else } \\
\text { you'd like to add? }\end{array}$ & $\begin{array}{l}\text { What do you like about the new } \\
\text { Physiotherapy extended role service? } \\
\text { Are there any aspects of the service } \\
\text { that you would change? } \\
\text { Has the inclusion of the physiotherapist } \\
\text { freed your time up for other tasks? } \\
\text { Has your inclusion of the } \\
\text { physiotherapist improved your } \\
\text { satisfaction with service provision? } \\
\text { Has the inclusion of the physiotherapist } \\
\text { eased your workload? } \\
\text { Are you satisfied with the } \\
\text { physiotherapist's assessment and } \\
\text { treatment skills to undertake this new } \\
\text { role? } \\
\text { Are there areas in which you feel the } \\
\text { physiotherapist needs to improve? } \\
\text { Is the communication from the } \\
\text { physiotherapist timely and appropriate? } \\
\text { Do you feel that the extended } \\
\text { scope physiotherapist impacted on } \\
\text { the patient's journey through the } \\
\text { department and if so, how? } \\
\text { Do you believe that the inclusion of the } \\
\text { physiotherapist impacted on the quality } \\
\text { of patient care and can you provide } \\
\text { examples if you believe that it has? } \\
\text { Is there anything else you'd like to add? }\end{array}$ \\
\hline
\end{tabular}


the intent of the evaluation. They brought skills in quantitative and qualitative data collection, analysis, and reporting. The researchers collaborated on interpretation of findings from all qualitative and quantitative data, to ensure that it was interpreted openly, transparently, and in context.

\section{Quantitative data reporting}

Means and measures of variability (standard deviation [SD], $95 \%$ confidence interval $[\mathrm{CI}]$ ) were used to describe equal interval data, and percentages were used to describe categorical data. Descriptive frequencies of diagnostic classifications were calculated for patients who consulted the different types of ED health care providers. Comparisons were made between ED providers of LoS and LoW with national and ATS category targets, using analysis of variance (ANOVA), 95\% CIs or chi-square tests as appropriate. Significant differences between datasets was set at $P<0.05$. Trend analysis was conducted over time using $r^{2}$ values. The impact on these targets of the ESoP-PT shift pattern was assessed. Patterns in presentations and compliance with NEAT targets were assessed graphically, and using trend analysis.

\section{Qualitative data reporting}

We used a descriptive approach for all qualitative data. Responses to the semi-structured interviews regarding patient satisfaction were analyzed by reporting the percentage of respondents providing different responses to questions. Examples of particularly illustrative responses to questions were extracted as direct quotations from interview transcripts. This analysis was undertaken using the pragmatic approach described by Huberman et al. ${ }^{4}$

\section{Adverse events}

Poor outcomes from care for all ED health providers were identified in two ways: as re-presentations for the same diagnosis within the next 48 hours, and patient complaints. The re-presentations were first assessed to exclude the visits that were for "check ups", an example includes a wound/dressing check for the original injury. Thus the diagnosis for the second visit was determined, and if it was for the same complaint, the patient notes were accessed. Re-presentation data were treated quantitatively. The patient complaints were treated qualitatively. Complaints were captured through reports of patient conversations with triage nurses, and through the formal hospital complaints process. Again using the Huberman et $\mathrm{al}^{4}$ approach, the central theme(s) of the complaints were identified and collated.

\section{Findings}

\section{Patient demographics}

During the period of the evaluation, in total, there were 51,223 episodes of care for Category 3, 4, or 5 which were treated in ED, with 13,495 seen in Fast Track. Of them $836(6.19 \%)$ were treated by the ASoP-PT. Of these patients $98.2 \%$ presented once only, with the remainder presenting twice, for different conditions. Age of patients ranged from younger than 1 year to 88 years (median age 26 years $[25 \%-75 \%, 16-40$ years $])$.

\section{ASoP-PT service availability}

The ASoP-PT worked on average, ten shifts per fortnight, in shift patterns (three day and seven evening shifts). Median total hours per fort night worked was 73 .

\section{ASoP-PT patient throughput}

The median patient throughput for the ASoP-PTper month was $72(25 \%-75 \%, 64-77)$. The median age of patients seen in any 1 month was 30 years (17-56 years). Right from service inception, there was high demand for the service, and demand increased overall by $2 \%\left(r^{2}=0.02\right)$ through out the evaluation period (see Figure 1). The aberration in patient numbers at February 2012 reflected ASoP-PT holidays. To examine patient's throughput related to service availability, we excluded February and considered two randomlychosen months (March and August 2012). In March 2012, there were 76 total patients, seen in eleven evening shifts (average five patients/shift [SD 2]), and five day shifts (average four patients/shift [SD 2]). In August 2012 there were 98 total patients, seen in 15 evening shifts (average six patients/shift [SD 3]) and three day shifts (average five patients/shift [SD 2]). While these per-shift numbers are small and reflect 2 months only of the ten comparable ones in the evaluation period, they suggest that the shift pattern of

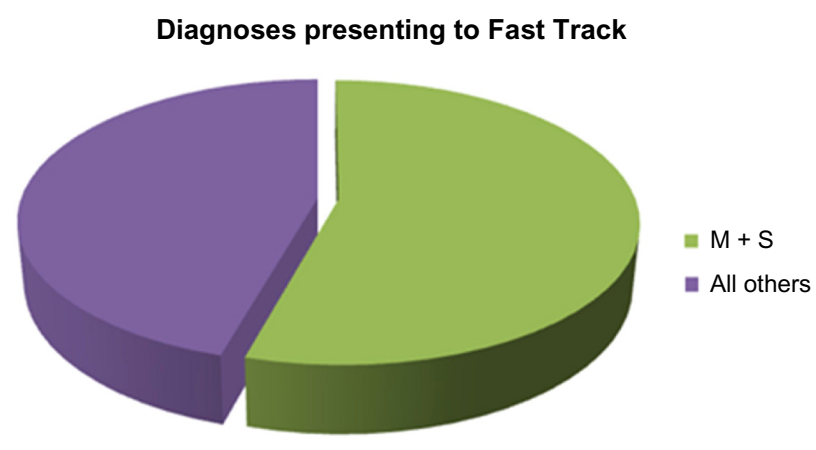

Figure I Break-down of clinical load in "Fast Track" area of emergency department. Notes: M, diseases of the musculoskeletal system and connective tissue; S, injury, poisoning, and certain other consequences of external causes. 
Table 4 Workload presentations by category

\begin{tabular}{llll}
\hline $\begin{array}{l}\text { Triage } \\
\text { category }\end{array}$ & $\begin{array}{l}\text { Number of } \\
\text { patients }\end{array}$ & $\begin{array}{l}\% \text { of } \\
\text { workload }\end{array}$ & $\begin{array}{l}\text { Average age of } \\
\text { patients }\end{array}$ \\
\hline 2 & 2 & 0.2 & 21,81 years \\
3 & 54 & 6.5 & 29.1 (SD 19.0, ages 4-80) \\
4 & 571 & 68.3 & 29.7 (SD 19.0, ages 2-88) \\
5 & 205 & 24.5 & 30.4 (SD 17.9, ages I-85) \\
\hline
\end{tabular}

Note: Two outliers and two representation cases were removed from analysis. Abbreviation: SD, standard deviation.

the ASoP-PT did not unduly influence throughput or volume over the time of the evaluation.

\section{ASoP-PT patient triage (ACEM) categories}

As anticipated, the ED PT dealt mainly with patients in ACEM Categories 4 (68.3\%) or 5 (24.5\%) (see Table 4). In his total workload, he also consulted Category 2 and 3 patients ( $0.2 \%$ and $6.5 \%$ respectively). Given the descriptions of the ATS categories in Table 1, on review some of these may well have been misclassified at triage point.

\section{ASoP-PT compliance with national targets}

Benchmarked data in each ACEM category are reported in Table 5, which reports LoS, and LoW for the ASoP-PT. This indicates that for ACEM Categories 3-5 the PT performed in line with the indicators, with at least $75 \%$ patients seen within the required ATS target.

\section{Comparing LoW and LoS data between shifts where the ASoP-PT was present or not}

We considered whether average LoS and LoW times $(95 \% \mathrm{CI})$ differed between day and evening shifts when the ASoP-PT

Table 5 Outcomes compared with national targets

\begin{tabular}{|c|c|c|c|}
\hline & Hours (SD) & $\begin{array}{l}68 \% \text { individuals } \\
\text { seen between }\end{array}$ & $\begin{array}{l}\% \text { seen within } \\
\text { NEATs (4 hours) }\end{array}$ \\
\hline \multicolumn{4}{|c|}{$\begin{array}{l}\text { Average length of stay (SD) per ATS category for the } \\
\text { emergency department ASoP physiotherapist }\end{array}$} \\
\hline ATS Cat 2 & 03:14 (II mins) & $3: 03$ and $3: 25 \mathrm{hrs}$ & 50.0 \\
\hline ATS Cat 3 & 02:04 (5 mins) & $\mathrm{I}: 59$ and $2: 09 \mathrm{hrs}$ & 87.5 \\
\hline ATS Cat 4 & 02:05 (5 mins) & $2: 0$ and $2: 1 \mathrm{hrs}$ & 92.5 \\
\hline ATS Cat 5 & 0I:59 (7 mins) & $\mathrm{I}: 52$ and $2: 06 \mathrm{hrs}$ & 90.9 \\
\hline \multicolumn{4}{|c|}{$\begin{array}{l}\text { Average length of wait per ATS category for the emergency } \\
\text { department physiotherapist }\end{array}$} \\
\hline ATS Cat 2 & $00: 08$ (2 mins) & 6 and 10 mins & 50.0 \\
\hline ATS Cat 3 & 00:43 (5 mins) & 38 and 48 mins & 75.0 \\
\hline ATS Cat 4 & 00:45 (3 mins) & 42 and 48 mins & 77.6 \\
\hline ATS Cat 5 & 00:54 (3 mins) & $5 \mathrm{I}$ and $57 \mathrm{mins}$ & 90.4 \\
\hline
\end{tabular}

Abbreviations: SD, standard deviation; ATS, Australian Triage Scales; ASoP, advanced scope of practice; Cat, category; mins, minutes; hrs, hours; NEATs, Australian National Emergency Access Targets. was present or not. This analysis was conducted for patients in ATS Categories 4 and 5 who presented with a musculoskeletal complaint (International Classification of Diseases [ICD]-10 classification $\mathrm{M}$ and $\mathrm{S}$ ).

The analysis showed that when the ASoP-PT was present, there was significantly shorter LoW and LoS (compared to the shifts when the ASoP-PT was absent). Significant differences can be observed in Figures 2 and 3 between LoW and LoS times with and without the ASoP-PT being present in the shift, by no overlap in $95 \%$ CIs. Moreover these figures demonstrate consistency of performance between shift types when the ASoP-PT was present (he performed similarly in day and evening shifts).

\section{Compliance with national ED performance targets ACEM targets}

In day shifts when the PT was absent, the targets were met $93.1 \%$ of the time for patients with musculoskeletal complaints, while in the evening shift when the PT was absent they were met $95.6 \%$ of the time. Conversely, in all day and evening shifts when the ASoP-PT was present, the targets were met $100 \%$ of the time. There was however, no significant difference in compliance overall with ACEM targets, with and without the ASoP-PT being present.

\section{NEAT}

In day shifts when the PT was absent, NEAT was met $87.8 \%$ of the time for patients with musculoskeletal complaints, while in the evening shift when the PT was absent it was met $92.2 \%$ time. Conversely, in the day shifts when the ASoP-PT was present, NEAT was met $100 \%$ of the time and in the evening shift when the PT was present it was met $98.2 \%$ of the time. There was also no significant difference overall in compliance with NEAT targets, with and without the ASoPPT being present.

\section{Nature of contact}

The majority of patients had primary contact with the ASoPPT ( $\mathrm{N}=793$ [95\%]), with the remainder $(\mathrm{N}=43[5 \%])$ having secondary contact. This reflected the situation where patients were first seen by another health care provider, then referred to the ASoP-PT for specialist management.

\section{Imaging and prescribing}

Table 6 lists the total number over the evaluation period, of imaging requests, and medications prescribed (by a medical officer after discussions with the ASoP-PT). Month-by-month 


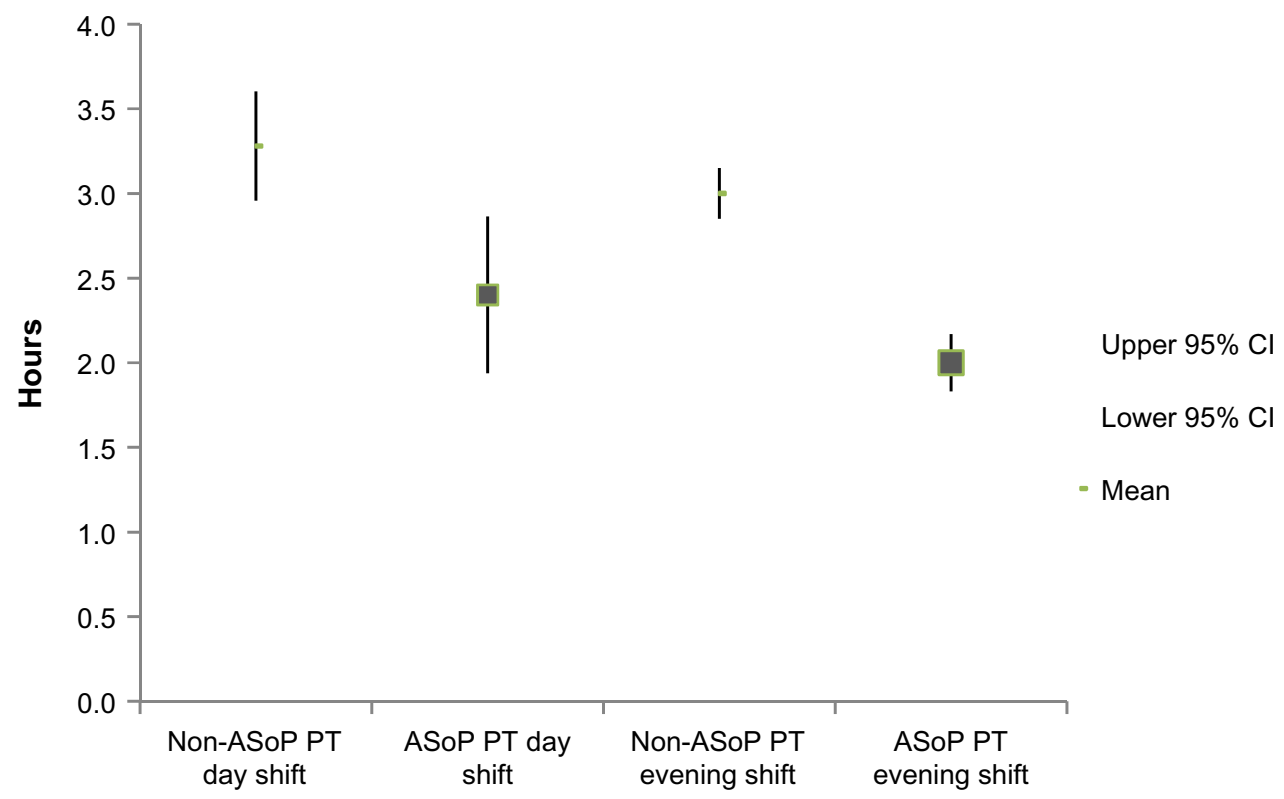

Figure 2 Mean length of stay ( $95 \%$ confidence interval) for ACEM triage Category 4 and 5 patients for day and evening shifts, with and without, the advanced scope practice emergency department physiotherapist present.

Abbreviations: ASoP, advanced scope of practice; PT, physiotherapist; Cl, confidence interval; ACEM, Australasian College for Emergency Medicine.

variations were minimal. This indicates a consistent volume of imaging and/or prescribing needs with respect to the total number of patients each month $(\%$ provision per total workload between $50 \%$ and $70 \%$ ).

The frequency of presentation of patients with different diagnostic categories is reported in Figure 4. This figure illustrates that the most common ICD category encountered in ED patients in ACEM Categories 4 and 5 for all service providers was ICD code S (Injury, poisoning, and certain other consequences of external causes [6478]), followed by ICD code M (Diseases of the musculoskeletal system and connective tissue [1554]). Figure 4 demonstrates the frequency of consultation of patients with each ICD code across each health professional group.

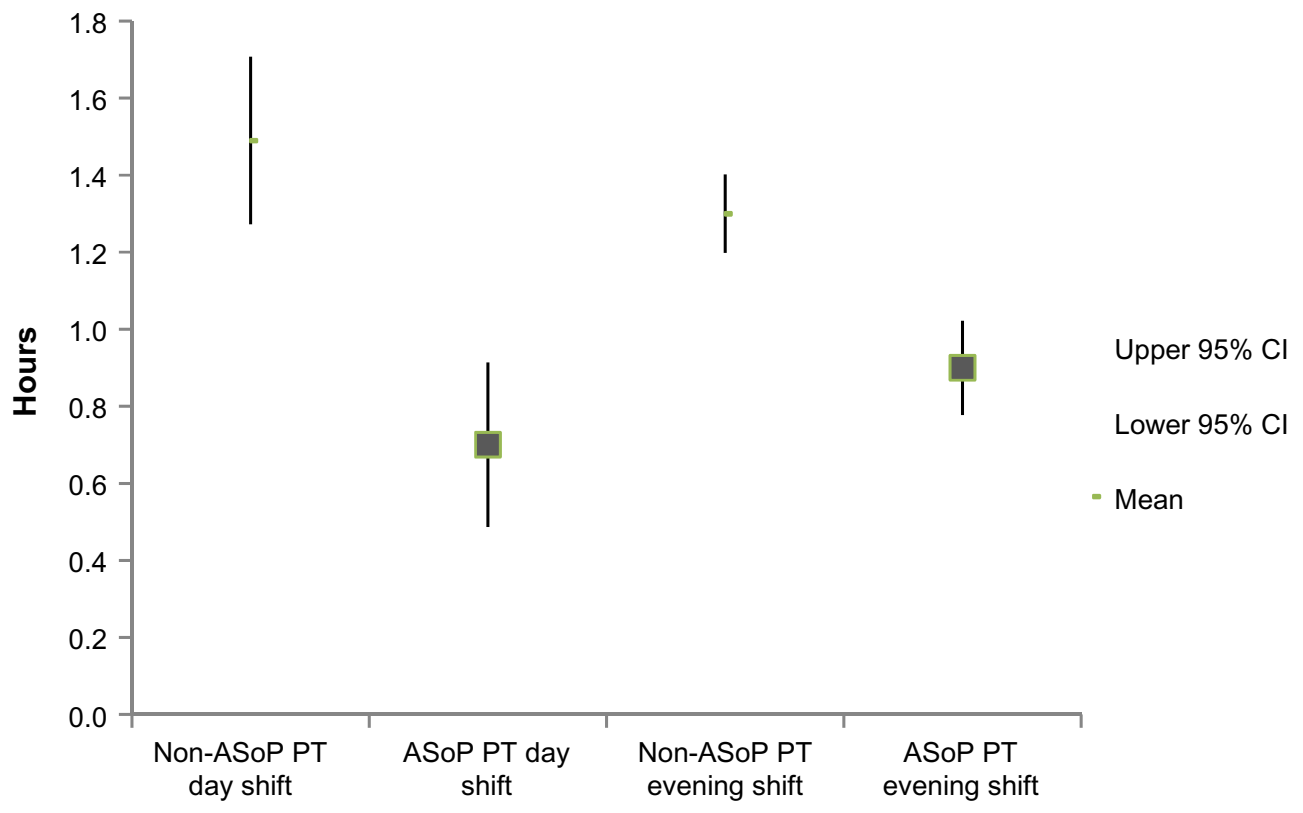

Figure 3 Mean length of wait (LoW) ( $95 \%$ confidence interval) for ACEM triage Category 4 and 5 patients in day and evening shifts, with and without, the emergency department physiotherapist present.

Abbreviations: ASoP, advanced scope of practice; PT, physiotherapist; Cl, confidence interval; ACEM, Australasian College for Emergency Medicine. 
Table 6 Imaging and prescribing activities undertaken by the emergency department physiotherapist

\begin{tabular}{lll}
\hline Imaging ordered & N & \% PT contact \\
\hline X-ray & 577 & 72.8 \\
CT & 31 & 3.9 \\
MRI & 10 & 1.3 \\
US & 19 & 2.4 \\
Assisted Imaging Interpretation & $46 \mathrm{I}$ & 58.1 \\
Medications discussed with, and subsequently prescribed by, \\
a medical officer \\
lbuprofen \\
Naproxen & 55 & 6.9 \\
Panadeine Forte & 3 & 0.4 \\
Panadol & 165 & 20.8 \\
Endone & 137 & 17.3 \\
Lignocaine & 73 & 9.2 \\
\hline
\end{tabular}

Abbreviations: PT, physiotherapist; CT, computed tomography; MRI, magnetic resonance imaging; US, ultrasound.

\section{Targets comparing health care provider performance}

Table 7 reports on LoW and LoS data over all relevant triage categories, for the ASoP-PT since service commencement, compared with doctors', advanced care nurses', and nurse practitioners' performance. The ASoP-PT had the highest percentage compliance with LoW and LoS national targets within the evaluation period, however this difference was not significant $(P>0.05)$.

\section{Adverse events}

There were no reports of significant adverse events from the activities of the ASoP-PT. Two people represented for management of the same condition within 48 hours. One person represented to have their cast re-applied. Another represented within 48 hours with the same condition. There were no reports/complaints from patients.

\section{Stakeholder perspectives}

The ASoP-PT service was met with approval by doctors, who believed it presented a viable safe alternative to medical care. This is evidenced by a quote from a member of the ED senior medical team:

\begin{abstract}
The ED doctors are supportive of the ASoP physiotherapy role as it provides an alternative, effective and time efficient management option for musculoskeletal presentations to the ED. This has been particularly noticeable as the ASoP physiotherapist has become competent in more advanced skills such as independently reviewing X-rays. In addition to this, the musculoskeletal skills of the ASoP physiotherapist offers an additional training and education opportunity for the doctors and nurses in ED. The ED ASoP physiotherapist is an integrated and accepted member of the ED team.
\end{abstract}

\section{Other staff perspectives}

Two advanced care nurses provided their views, which were positive regarding the improved quality, timeliness, access, and patient flow resulting from the introduction of the new physiotherapy service. Both interviewees noted that the presence of specialist PT with musculoskeletal expertise in ED provided a previously unavailable resource:

The ability to tap into information that either the RMO doesn't have or in fact the consultants don't have, because we are very low in our skills of musculoskeletal areas but working with one on one is much better than just ringing up

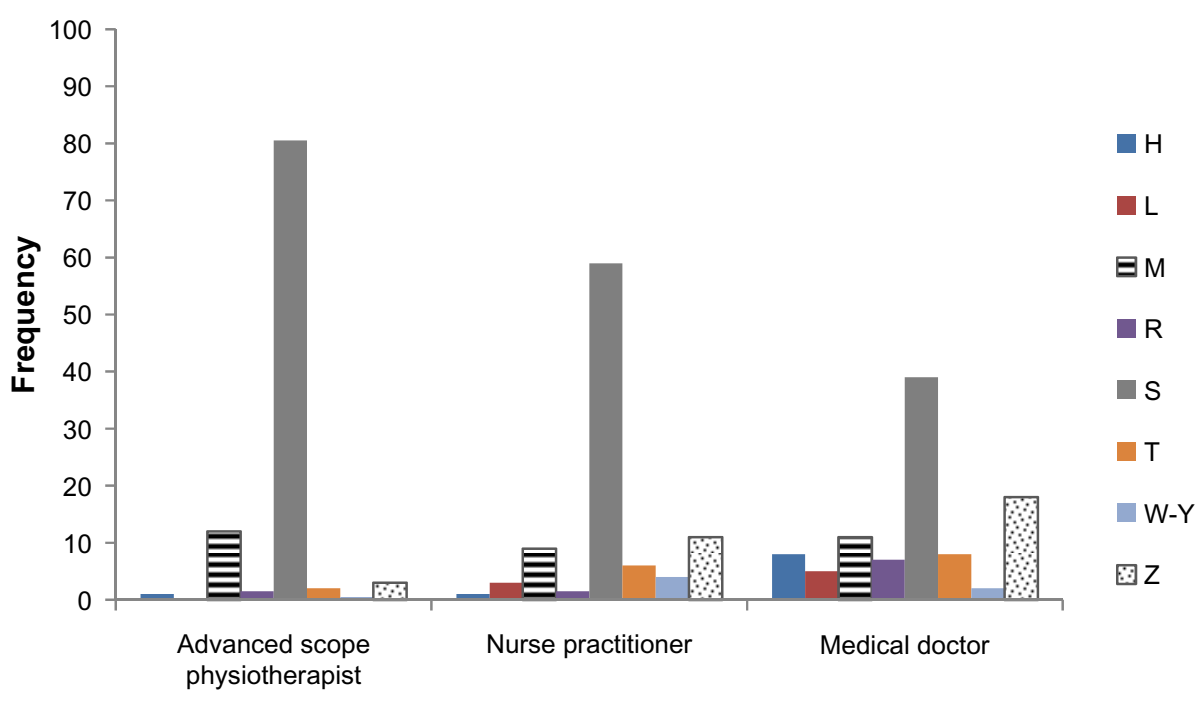

Figure 4 Frequency of consultation with patients with International Classification of Diseases codes for each health professional group. Notes: See Table 2 for the explanation of each letter (ICD codes). 
Table 7 Comparison of average \% across Categories 3-5, of patients seen within NEAT (LoW) and ACEM (LoS) targets comparing emergency department health care providers

\begin{tabular}{lll}
\hline Seen by & $\begin{array}{l}\text { \% LoW within } \\
\text { target across } \\
\text { ACEM categories }\end{array}$ & $\begin{array}{l}\text { \% LoS within } \\
\text { target across } \\
\text { NEAT categories }\end{array}$ \\
\hline $\begin{array}{l}\text { Doctor } \\
\text { ED advanced scope }\end{array}$ & 50.8 & 72.9 \\
physiotherapist & 75.8 & 93.1 \\
Advanced care nurse & 70.0 & \\
Nurse practitioner & 44.8 & 81.3 \\
\hline
\end{tabular}

Abbreviations: NEAT, Australian National Emergency Access Target; LoW, length of wait; ACEM, Australasian College for Emergency Medicine; LoS, length of stay; $E D$, emergency department.

a physio and asking them to fix a problem. Yes, they're much better at assessing sometimes than doctors are. I think.

I have seen so many matters approaching the physiotherapists. Not necessarily in the extended scope of practice physios but even the other like back pain, you find doctors don't really have that confidence in treating, which the physiotherapists have.

Such was the success of the initiative that staff indicated the need for a greater presence of the ASoP-PT. For instance, matching available (shift) times to demand was noted as an area requiring improvement.

Well it's badly needed in the late afternoons is our peak time for musculoskeletal areas. And that's when we tend to get a backlog anyway, just with our normal workflow. So yes, we do need them more so in the late afternoons.

Overall, timeliness and access to care was noted as having improved considerably as a result of introduction of the ASoP-PT:

[...] for example in the past the RMO who has absolutely no musculoskeletal background, they will say "Go home and see your physiotherapist, privately", but now we can actually start treatment in the department and extend that to sending them off to the most appropriate physiotherapist or the most appropriate tests requirement. Because we often send people, or we used to often send people back to their GPs [general practitioners], who also have very limited musculoskeletal history. And then they may get around in 2 or 3 weeks' time to send them off to a physiotherapist. So the time to treatment has shortened and the quality of treatment has increased.

\section{Patient perspectives}

Overall, ten of the eleven patients interviewed were satisfied with the quality and the speed of the service they received from the ASoP-PT in ED.
Oh just the explaining to me, what was going on and what was happening and just all the care taken, yeah [...] it was great.

$\mathrm{Ah}$, [I liked] the recommendation to go and see a specialist because I am now booked in for surgery next Thursday.

Thoroughness of the physiotherapy examination was noted by approximately half the patient interviewees. This was sometimes compared with less thorough interactions that patients had previously experienced with other ED staff:

Um, I just liked the fact [he] followed through with it and yeah, he made sure that I knew exactly what was going on and everything and advised - you had the results of the X-rays, the best treatment option, what my other options were.

However approximately half the patients were not aware initially that they were consulting a PT. This became apparent during the course of the consultation.

No, I thought [named the PT], whoever he was, because he was the one who picked me up and gave me this care or treatment if you like, I kind of thought he was a doctor if you know what I mean because really did [...] he went out of his way to organize the, what do you call 'em, the ultrasound the next day on a Sunday for God's sake. And he also observed, look getting an MRI is the best thing to do but they have it'd take you too long via our [usual] system.

Lengthy waiting times and less than quality interaction with other staff were noted:

Oh as I said before, I'm fairly happy with it. I was well looked after and that. I might make that complaint about the nurses not really paying attention but like I understand that I have to wait with the severity of [my injury] I asked for a blanket because I was a bit cold and after an hour I got nothing so $[\ldots]$ but the doctors were quite fine.

\section{Discussion}

This paper reports new knowledge, gleaned from a pilot project of 11 months - 53 weeks (accounting for annual leave) of an ED-based specialist (advanced scope) physiotherapy service. The evaluation provides information on a large consecutively sampled cohort of patients mostly in ACEM triage Categories 4 and 5. It compares physiotherapy service delivery with that of other ED health care providers, for the same triage category patients and diagnostic classifications, when the ASoP-PT was absent. The paper highlights that having an ED ASoP-PTon shift produced significantly shorter LoS and LoW times overall than when he was not on shift; however, there was similar compliance overall with national 
performance indicators over these shifts. Comparing individual health care providers' service delivery, the specialist PT performed better (but not significantly so) than the other providers, for LoW and LoS. Patients and staff were mostly satisfied with the service, particularly highlighting the value of having a skilled musculoskeletal therapist in ED. No adverse events were reported.

Reasons for not complying fully with indicators need to be further examined; however they may reflect issues outside the control of the PT, such as speed of imaging and waiting for a medical doctor to progress medicine use. The current legal requirement that medicines must be prescribed by a medical doctor, after consultation with the PT, is inefficient. Had the PT been legally able to prescribe medicines independently, compliance with the ED performance targets may have been better for both PT and doctors. Despite this drawback, the presence of the ASoP-PT in ED raised the overall staff compliance with the ACEM and NEAT performance indicators. Patients noted comprehensive assessment and advice regarding self-management, or options for further treatment as quality aspects of the ASoP-PT service, and reasons for their satisfaction. Given the lack of adverse events, the evaluation suggests that the ED ASoP-PT's service was as safe as his medical and nursing peers.

Perhaps the most useful outcome of this evaluation was confirmation that ED care for many patients in ACEM Categories 4 and 5 can be independently managed by an appropriately trained PT, particularly one working in an ASoP capacity. With legislative changes to allow this PT to work in extended scope roles, efficiencies could improve. The body of Australian research regarding the potential effectiveness of an extended scope physiotherapy role in ED supports this finding ${ }^{12-17}$ Such a position could de-load busy medical doctors and nurses, and provide them with the time to work with patients in more urgent ACEM Categories 1-3, for conditions that are not appropriate for physiotherapy intervention. Based on the findings of this research, cost effectiveness studies are now warranted to test whether budgetary savings result from this service innovation, to determine whether there is a link between cost savings and enhanced compliance with performance targets, as well as whether a permanent advanced or extended scope physiotherapy service in ED improves compliance across all ED performance targets for all triage patient categories.

\section{Conclusion}

Using novel workforce redesign strategies such as PTs working in specialist and extended roles potentially offer much in assisting hospital EDs to meet performance targets with dwindling medical and nursing workforce, and increasing patient demand. PTs independently applying their specialist musculoskeletal skills as primary contact practitioners in ED is a sensible way to provide patients with non-life threatening musculoskeletal problems with efficient and high-quality care. This relieves pressures on doctors and nurses to deal with other body systems and more serious health presentations.

Addressing the legislative changes required to allow appropriately-trained PTs to directly advise on, prescribe, and administer medicines in their management of ED patients is the next step to providing ED patients with another efficient, credible, evidence-based treatment option.

\section{Acknowledgments}

Tim McGrath for maintaining the data log, Karen Murphy for supporting the project, and Lisa Gilmore for physiotherapy discipline management of the advanced scope physiotherapy practice role in the ED.

\section{Disclosure}

The authors have no conflicts of interest to disclose.

\section{References}

1. McClellen CM, Cramp F, Powell J, Benger JR. A randomised trail comparing the clinical effectiveness of different emergency department healthcare professionals in soft tissue injury management. BMJ Open. 2012;2(6).pii:e001092.

2. McPherson K, Kersten P, George S, et al. A systematic review of evidence about extended scope roles for allied health professionals. J Health Serv Res Policy. 2006;11(4):240-247.

3. Stanhope J, Grimmer-Somers K, Milanese S, Sumar S, Morris J. Extended scope physiotherapy roles for orthopaedic outpatients: an update systematic review of the literature. J Multidiscip Healthc. 2012;5:37-45.

4. Huberman et al. 1994.

5. Council of Europe [homepage on the Internet]. European working time directive. Council of Europe; 1998. Available from: http://webarchive. nationalarchives.gov.uk; www.dh.gov.uk/en/Managingyour organisation/Workforce/Workforceplanninganddevelopment/European workingtimedirective/DH_077304. Accessed November 21, 2013.

6. Kersten P, McPherson K, Lattimer V, George S, Breton A, Ellis B Physiotherapy extended scope of practice - who is doing what and why? Physiotherapy. 2007;93(4):235-242.

7. Hattam P. The effectiveness of orthopaedic triage by extended scope physiotherapists. Clinical Governance: An International Journal. 2004; 9(4):244-252.

8. Hattam P, Smeatham A. Evaluation of an orthopaedic screening service in primary care. Clinical Performance and Quality Healthcare. 1999;7(3):121-124.

9. Maddison P, Jones J, Breslin A, et al. Improved access and targeting of musculoskeletal services in northwest Wales: Targeted early access to musculoskeletal services (TEAMS) programme. BMJ. 2004;329(7478): 1325-1327.

10. Atkins, E. (2003). Physiotherapists' experience of implementing their injection therapy skills. Physiotherapy (89). 
11. Dawson LJ, Ghazi F. The experience of physiotherapy extended-scopepractitioners in orthopaedic outpatient clinics. Physiotherapy. 2004; 90(4):210-216.

12. Anaf S, Sheppard L. Physiotherapy as a clinical service in emergency departments: a narrative review. Physiotherapy. 2007;93(4):243-252.

13. Anaf S, Sheppard L. Lost in translation? How patients perceive the extended scope of physiotherapy in the emergency department. Physiotherapy. 2010;96(2):160-168.

14. Crane J, Delany C. Physiotherapists in emergency departments: Responsibilities, accountability and education. Physiotherapy. 2013;99(2): 95-100.

15. Gill SD, Stella J. Implementation and performance evaluation of an emergency department primary practitioner physiotherapy service for patients with musculoskeletal conditions. Emerg Med Australas. 2013; 25(6):558-564.

16. Gilmore LG, Morris JH, Murphy K, Grimmer-Somers K, Kumar S. Skills escalator in allied health: a time for reflection and refocus. Journal of Healthcare Leadership. 2011;3:53-58.

17. Kilner E, Sheppard L. The 'lone ranger': a descriptive study of physiotherapy practice in Australian emergency departments. Physiotherapy. 2010;96(3):248-256.

18. ÁCT Health. Physiotherapy extended scope of practice: Phase 1. Final report. Canberra: Australian Government; 2008.

19. Australian Institute of Health and Welfare [homepage on the Internet]. Australian hospital statistics: National emergency access and elective surgery targets. AIHW; 2012. Available from: http://www.aihw. gov.au/WorkArea/DownloadAsset.aspx?id=60129542732. Accessed November 12, 2013

20. Woolf AD, Pfleger B. Burden of major musculoskeletal conditions. Bull World Health Organ. 2003;81(9):646-656.

21. Oldmeadow LB, Bedi HS, Burch HT, Smith JS, Leahy ES, Goldwasser M. Experienced physiotherapists as gatekeepers to hospital orthopaedic outpatient care. Med J Aust. 2007;186(12): 625-628.

22. Morris JH, Grimmer K. Non-medical prescribing by physiotherapists: Issues reported in the current evidence. Man Ther. 2014;19(1): 82-86.

23. Morris J, Grimmer-Somers K, Kumar S, et al. Effectiveness of a physiotherapy-intiatied telephone triage of orthopaedic waitlist patients. Patient Relat Outcome Meas. 2011;2:151-159.

24. Australian Physiotherapy Association. APA Position Statement: Scope of Practice. APA; 2009. Available from: http_:/www.physiotherapy.asn. au/DocumentsFolder/Advocacy_Position_Scope_of_Practice_2009. pdf. Accessed July 14, 2013.
25. Australasian College for Emergency Medicine (ACEM). Policy on Australasian Triage Scale. ACEM; 2013. Available from: Accessed July 7, 2013.http://www.acem.org.au/media/P06_Policy_on_ATS_v4_Jul-13_. pdf.

26. Browder DA, Erhard RE. Decision making for a painful hip: a case requiring referral. J Orthop Sports PhysTher. 2005;35(11):722-729.

27. Stowell T, Cioffredi W, Greiner A, Cleland J. Abdominal differential diagnosis in a patient referred to as physical therapy clinic for low back pain. J Orthop Sports Phys Ther. 2005;35(11):755-764.

28. Troyer MR. Differential diagnosis of endometriosis in a young woman with nonspecific low back pain. PhysTher. 2007;87(6):800-810.

29. McClellen CM, Cramp F, Powell J, Benger JR. A randomised trial comparing the cost effectiveness of different emergency department professionals in soft tissue injury management. BMJ Open. 2013;3(1). pii:e001116.

30. Richardson B, Shepstone L, Poland F, Mugford M, Finlayson B, Clemence N. Randomised controlled trail and cost consequences study comparing physiotherapy assessment and management with routine practice for selected patients in an accident and emergency department of an acute hospital. Emerg Med J. 2005;22(2):87-92.

31. Jibuike OO, Paul-Taylor G, Maulvi S, Richmond P, Fairclough J. Management of soft tissue knee injuries in an accident and emergency department: the effect of the introduction of a physiotherapy practitioner. Emerg Med J. 2003;20(1):37-39.

32. National Health Performance Authority [homepage on the Internet]. (2013b). Emergency department services: Waiting times for July 2011-June 2012. NHPA; 2013. Available from: http://www.myhospitals. gov.au/hospital/the-canberra-hospital/services/emergency-department/ waiting-times. Accessed September 17, 2013.

33. National Health Performance Authority [homepage on the Internet]. (2013a). Emergency department services: Time in the department from arrival to departure for July 2011-June 2012. NHPA; 2013. Available from:http://www.myhospitals.gov.au/hospital/the-canberrahospital/services/emergency-department/time-in-emergency. Accessed September 17, 2013.

34. Australian Government Productivity Commission. (2012). Report on Government services 2012.

35. Australian Capital Territory. Medicines, Poisons and Therapeutic Goods Act (2008).

36. World Health Organization [homepage on the Internet]. International statistical classification of diseases and related health problems 10th revision. WHO. Available from: http://apps.who.int/classification/ icd10/browse/2010/en. Accessed November 12, 2013. 


\section{Supplementary material \\ State and territory legislation documents relating to medicines}

- Victorian Drugs, Poisons and Controlled Substances Act 1981:

http://www.legislation.vic.gov.au/Domino/Web Notes/ LDMS/LTObject Store/LTObjSt7.nsf/DDE300B846E ED9C7CA257616000A3571/3E94BBFB45B6850AC A257A700000A6DF/\$FILE/81-9719aa099\%20authorised.pdf

- Controlled Substances Act 1984 - South Australia:

http://www.legislation.sa.gov.au/LZ/C/A/ CONTROLLED \%20SUBSTANCES\%20ACT $\% 20$ 1984/2004.09.29/1984.52.PDF

- Health (Drugs and Poisons) Regulation 1996 - Queensland:

http://www.legislation.qld.gov.au/LEGISLTN/ CURRENT/H/HealDrAPoR96.pdf

- Poisons Act 1971 - Tasmania:

http://www.thelaw.tas.gov.au/tocview/index.

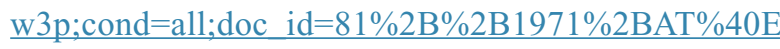
$\underline{\mathrm{N} \% 2 \mathrm{~B} 20100214000000 ; \text { histon }=; \mathrm{prompt}=; \mathrm{rec}=; \text { term }=\mathrm{p}}$ oisons $\% 20$ act
- Poisons and Therapeutic Drugs Act 1966 - New South Wales:

http://www.legislation.nsw.gov.au/maintop/view/inforce/ $\underline{\mathrm{act}+31+1966+\mathrm{cd}+0+\mathrm{N}}$

- Poisons and Therapeutic Goods Regulation 2002:

http://www.legislation.nsw.gov.au/fullhtml/inforce/ $\underline{\text { subordleg }+639+2002+\text { FIRST }+0+\mathrm{N}}$

- Northern Territory Poisons and Dangerous Drugs Act: http://www.austlii.edu.au/au/legis/nt/consol act/ padda296/

- Western Australia Poisons Act 1964:

http://www.austlii.edu.au/au/legis/wa/consol act/ pa1964121/

- Poisons Regulations 1965:

http://www.austlii.edu.au/au/legis/wa/consol reg/ pr1965230/s40.html

- Australian Capital Territory - Medicines, Poisons and Therapeutic Goods Act 2008:

http://www.legislation.act.gov.au/a/2008-26/current/ pdf/2008-26.pdf.
Patient Related Outcome Measures

\section{Publish your work in this journal}

Patient Related Outcome Measures is an international, peer-reviewed, open access journal focusing on treatment outcomes specifically relevant to patients. All aspects of patient care are addressed within the journal and practitioners from all disciplines are invited to submit their work as well as healthcare researchers and patient support groups.

\section{Dovepress}

The manuscript management system is completely online and includes a very quick and fair peer-review system. Visit http://www.dovepress. com/testimonials.php to read real quotes from published authors. 